\title{
A vOZ DOS IMIGRADOS: UMA ANÁLISE DO FILME La mia Classe (2013) de Daniele Gaglianone
}

\author{
Maria Célia MartiRani *
}

RESUMO: O filme de Daniele Gaglianone La mia classe pode ser inserido na tradição cinematográfica italiana dos chamados "filmes sobre migração", porque se alinha aos que buscam representar a situação dramática daqueles que precisam se reinventar em terra estrangeira. Trata-se de uma obra que aponta a câmera para o mundo clandestino da imigração, deixando-o falar. Os protagonistas são todos amadores, não profissionais e se autorrepresentam, à exceção de Valerio Mastandrea, que faz o papel de um professor-voluntário de uma classe de Língua Italiana para imigrados. Não faltam, em La mia classe, temas que tratam do drama da viagem, do trauma da separação familiar, da perda de identidade e da sensação de não pertencimento, comuns às diásporas contemporâneas. Mas o mérito do filme está muito mais em sua proposta formal que temática. Sua força reside justamente na zona híbrida entre o documentário e a ficção: "docufiction" (NICHOLS, 2014), problematizando os níveis de representação do real (JAMESON), numa perspectiva metacinematográfica, em que o cinema reflete sobre o alcance e as limitações da própria arte de fazer cinema.

PALAVRAS-CHAVE: cinema italiano da migração; Daniele Gaglianone; docufiction; crise da representação

ABSTRACT: Daniele Gaglianone's film La mia classe can be inserted in the Italian film tradition of the so-called "migration films", because it aligns with those who seek to represent the dramatic situation of those who need to reinvent themselves in foreign land. It is a work that points the camera to the clandestine world of immigration, letting it speak. The protagonists are all amateurs, not professionals and self-represent, except for Valerio Mastandrea, who plays the role of a teacher-volunteer of an Italian language class for immigrants.There are many topics in La mia classe dealing with the tragedy of the journey, the trauma of family separation, the loss of identity and the sense of non-belonging common to contemporary diasporas. But the merit of the film is much more in its formal than thematic proposal. Its strength resides precisely in the hybrid zone between documentary and fiction: "docufiction" (NICHOLS, 2014), problematizing the levels of representation of the real (JAMESON), in a metacinematographic perspective, in which the cinema reflects on the scope and limitations of the art itself make movies.

KEY-WORDS: Italian migration cinema; Daniele Gaglianone; docufiction; representation crisis

"pispiti@yahoo.com.br

DOI: http://dx.doi.org/10.11606/issn.2238-8281.v0i37p17-27 
RIASSUNTO: Il film di Daniele Gaglianone La mia classe può essere inserito nella tradizione cinematografica italiana dei cosiddetti "film sulla migrazione" perché si allinea a quelli che cercano di rappresentare la situazione di chi ha bisogno di reinventarsi in una terra straniera. È un lavoro che punta la cinepresa sul mondo dell'immigrazione clandestina, lasciandolo parlare. Gli attori sono tutti non professionisti e si autorappresentano, ad eccezione di Valerio Mastandrea, che interpreta il ruolo di un insegnante di un corso di lingua italiana per immigrati. Non mancano ne La mia classe i problemi del dramma del viaggio, del trauma della separazione familiare, della perdita di identità e del senso di appartenenza, comuni alle diaspore contemporanee. Ma il merito del film si concentra molto di più nella sua proposta formale che in quella tematica. La sua forza sta proprio nella zona ibrida tra documentario e finzione, "docufiction" (NICHOLS, 2014) o nella discussione sui livelli attuali di rappresentazione (Jameson), in una prospettiva meta-cinematografica, in cui il film riflette sulle serie limitazioni della stessa arte di fare cinema.

PAROLE-CHIAVE: cinema della migrazione; Daniele Gaglianone; docufiction; crisi della rappresentazione. 
a mia classe (2013) é um filme ambientado em uma escola noturna para imigrados da periferia de Roma. $\mathrm{O}$ ator Valerio Mastandrea interpreta um professor de Língua e Cultura Italiana, cujos alunos - provenientes das mais diversas partes do mundo - atuam num processo de autorrepresentação: tratam-se de não atores que representam a si próprios, naquela situação específica de aprendizagem, fundamental para que possam se integrar no lugar de chegada.

Classificado por grande parte da crítica como um "docufiction", apresenta-se como instigante caso, em que a ficção se nutre de traços documentais, numa explícita investida no esmaecimento intencional das linhas demarcatórias de gênero (NICHOLS, 2014, p. 20-71).

Consta que, inicialmente, Gaglianone quisesse fazer uma espécie de versão italiana do filme Entre os muros da escola (no original Entre les murs) de Laurent Cantet, que venceu a Palma de Ouro em Cannes, em 2008. Ele afirma que, de fato, perseguia a ideia de criar um filme situado entre o documentário e a ficção, que conseguisse atingir o status de uma parábola dramática das histórias verdadeiras daqueles alunos e de suas dificuldades de interação. Mas, enquanto realizava o filme, algo inusitado ocorreu: "De fato, estávamos prontos para contar as histórias que representavam, de modo plausível, a condição de imigrados de alguns daqueles alunos, quando, de repente, o que era apenas uma ideia do roteiro acabou se tornando um fato real, que estava ocorrendo naquele preciso instante" (MARSHALL, 2014, p.71, trad. nossa).

É ainda o diretor quem revela que pensou seriamente em desistir de fazer o filme porque ele e toda a equipe acabaram por vivenciar uma situação contraditória de base, praticamente sem solução. Na prática, eles estavam prontos para contar as histórias da condição de alguns daqueles alunos imigrados, quando um imprevisto, aquilo que era apenas uma ideia do roteiro se tornava um fato real que passava a acontecer naquele momento. E continua:

Depois de muito pensar, decidimos estruturar o filme em dois níveis: um no qual Valerio Mastandrea interpreta o professor e um outro no qual se deixava claro que estávamos fazendo um filme. Estes dois níveis se imbricaram a tal ponto que, aos poucos, se tornaram incindíveis: o objetivo era fazer com que o espectador parasse de se perguntar ao que estava assistindo, se a um documentário, a um docufiction ou a um filme de ficção, simplesmente porque todas essas categorias deixavam de fazer sentido naquele contexto.

1 Entre les Murs (pt: A Turma/ br: Entre os Muros da Escola) é um filme francês vencedor da Palma de Ouro do Festival de Cannes em 2008. A história baseia-se no livro homônimo escrito por François Bégaudeau, que além de escritor, é também professor. O diretor Laurent Cantet convidou-o a estrelar o filme juntamente com um elenco formado por não-atores. Durante sete semanas as filmagens aconteceram no interior de uma escola no subúrbio de Paris. O resultado desse trabalho foi um filme exibido nos cinemas de quarenta e quatro países entre maio de 2008 e agosto de 2009 e presente em quatorze festivais de cinema. Disponível em: https://pt.wikipedia.org/wiki/Entre_les_murs. Acesso: 08/ 05/2017). 
Tratava-se também de propor uma reflexão sobre a natureza dual da imagem, que remete simultaneamente a dois universos que, não raro, tentamos separar, mas que, no fundo, são inseparáveis... O set se tornara uma alegoria do local fechado e aparentemente protegido, em que temos a tentação de permanecer, distanciados de uma vitalidade e de uma dor que imaginamos como "extras", como estrangeiras, mas que também nos pertencem porque provocadas diretamente pelo sistema econômico e social em que vivemos e do qual nos tornamos reféns (AGIS SCUOLA, s/d, on-line)

O "fato real" a que o diretor faz referência ocorre depois que muitos alunos já se haviam apresentado, com suas respectivas histórias de vida e diz respeito ao que virá a acontecer com o nigeriano Issa. A uma certa altura, tomamos conhecimento de que seu certificado de permanência vencera, o que é revelado ao professor, que não pode tomar nenhuma atitude concreta para ajudá-lo. Consequentemente, aquele aluno não poderá mais participar do set de filmagem, porque sem a posse do específico documento passa a ser clandestino.

Durante a filmagem, então, o real invade a cena abruptamente. Vemos o desespero do imigrado que, vindo a ser flagrado pela polícia, tem obrigatoriamente que ser deportado ao seu país de origem, o que, para ele, significa a morte.

A câmera - antes focalizada na rotina do que acontecia em sala de aula, com a participação dos alunos e do professor - parece perder o foco e se desestabiliza. E então, o diretor, alguns membros da equipe de filmagem e o professor perdem a sua função de profissionais do cinema e surgem, em cena, como seres humanos indignados diante do drama que a realidade lhes oferece para vivenciar: o da impotência de não poderem agir, diante do impedimento legal e do afastamento compulsório de Issa (que vem a ser preso, de fato). Diante do que está ocorrendo naquele preciso momento, Mastrandrea comenta com o diretor, em voz baixa: "Então, aquilo que estamos fazendo não serve para nada...” (MARSHALL, 2014, p. 71)

O que temos, portanto, é a explicitação do embaralhamento entre arte e vida, numa proposta de cinema que visa formalmente, sobretudo, instaurar a dúvida: estamos diante de uma representação fidedigna do real ou tudo não passa de ficção? Issa teria realmente sido impedido de filmar, teria realmente sido preso, causando a consternação de todos os participantes, ou estamos diante de mais um $\mathrm{jogo}^{2}$ que intenciona, no limite, romper definitivamente as barreiras entre a realidade que se quer representar e a que se pretende ficcionalizar? Real e ficcional seriam apenas as duas faces totalmente intercambiáveis da mesma moeda?

Claramente, o filme de Gaglianone pode ser inserido na longa tradição cinematográfica italiana dos, assim chamados, "filmes sobre migração", porque se alinha entre os que buscam representar a situação dramática daqueles que precisam se reinventar em terra estrangeira. Não faltam em La mia classe, temas que tratam do drama da viagem, do trauma da separação familiar, da perda de identidade e da sensação de não pertencimento, comuns às diásporas

2 A respeito, é interessante citar aqui a proposta do cineasta brasileiro Eduardo Coutinho no documentário Jogo de cena (2007), cuja investida cinematográfica visa, de certo modo, por em xeque as marcas delimitadoras e classificatórias do que poderia ser definido como "representação do real" x "representação do ficcional". 
contemporâneas. Todas essas questões surgem a partir dos depoimentos dados pelos alunos ao professor que a eles se abre generosa e solidariamente, numa postura que reflete, obviamente, a do diretor, na defesa da causa pró-imigrado.

Mas o mérito do filme está muito mais em sua proposta formal que temática. Sua força reside justamente nessa zona híbrida e movediça entre o documentário e a ficção, problematizando os níveis de representação do real, numa perspectiva metacinematográfica, em que o cinema reflete sobre o alcance e as limitações da própria arte de fazer cinema.

Ao explicitar os bastidores do modus operandi de que vai dispondo em seu fazer cinematográfico, Gaglianone rompe com o ilusionismo, analogamente ao que Brecht propunha no teatro, quanto ao que se convencionou denominar de quebrada quarta parede ${ }^{3}$. Assim agindo, convida o espectador a ver de bem perto a cena que ali se representa, fazendo cair por terra o efeito alienante que costumava iludi-lo.

O que acontece com Issa em La mia classe gera a desestabilização provocada pelo efeito de quebra do ilusionismo, apontando a uma invasão do real na cena cinematográfica, que também tira o espectador da posição cômoda do mero fruidor, exigindo-lhe cumplicidade e participação. Daí por que se trate de um filme totalmente coadunado com as principais tendências artísticas contemporâneas.

Com efeito, de acordo com o que observa Pedro Eduardo Pereira Salomão, atualmente o cinema tende a "ultrapassar as barreiras da pura ficcionalização e segue determinado a invadir o terreno a priori exclusivo do documentarismo". Além do mais:

O locus ocupado pela ficção no filme documental, bem como o locus do documentário na criação ficcional não estão mais claramente demarcados. O espaço reservado a cada um não se estabelece com transparência. Explorando justamente a dúvida é que o cinema contemporâneo convida o público a seu jogo “miseenscènico". (SALOMÃO, 2007, s/p)

O estudioso ainda ensina que, sobretudo, a partir dos anos noventa, a contaminação da ficção pelo tom documental teria servido para potencializar as fabulações. Daí porque o real representado não sirva ao ficcional, mas vá ao encontro dele, num processo de fusão: “Ao transitar pelo indiscernível, o realismo contemporâneo entrega ao espectador o poder de decisão: verdade ou mentira, realidade ou fabulação, documentário ou ficção?” (SALOMÃO, 2007, s/p)

O filme de Gaglianone trabalha exatamente nessa mesma linha de abordagem, insuflando, com vigor, a dúvida. O que resulta disso é que pouco importa se o que ocorre com Issa é "real

3 O ato de derrubar a quarta parede é usado no cinema, no teatro, na televisão e na arte escrita, e tem origem na teoria do teatro épico de Bertolt Brecht, que ele desenvolveu a partir e, curiosamente, para contrastar com a teoria do drama de Constantin Stanislavski. Refere-se a uma personagem dirigindo a sua atenção para a plateia, ou tomando conhecimento de que as personagens e ações não são reais. O efeito causado é que a plateia se lembra de que está vendo ficção e isso pode eliminar a suspensão de descrença. Muitos artistas usaram esse efeito para incitar a plateia a ver a ficção sob outro ângulo e assisti-la de forma menos passiva. Brecht estava ciente de que derrubar a quarta parede iria encorajar a plateia a assistir a peça de forma mais crítíca - o chamado "Efeito de Alienação". Para maior aprofundamento veja-se: ROSENFELD, Anatol. Brecht e o teatro épico. São Paulo: Perspectiva, 2012, p. 56-60. 
ou ficcional".

O ganho de tal proposta está, sobretudo, em trabalhar com a desestabilização da representação, que é também o afastamento da certeza, o enfraquecimento da verdade. E assim, de certo modo, em La mia classe, veremos, em mise em scène, a materialização do que Frederic Jameson entende como instabilidade do conceito de "realismo". Com efeito, para o eminente estudioso, os dois termos do slogan "representação da realidade" apontam a uma contradição de base, pois a ênfase a um conteúdo verdadeiro acaba sendo minimizada pelos artifícios de representação da própria obra:

Se o realismo confirma sua pretensão de ser uma representação do mundo correta ou verdadeira, ele, assim, deixa de ser um modo estético de representação e fica fora da esfera da arte. Por outro lado, se exploramos, enfatizamos ou colocamos em primeiro plano os artefatos artísticos com a captura da verdade do mundo, o "realismo" é desmascarado como um mero efeito-de-realismo ou efeito-de-realidade, e o real que ele pretendeu desvelar se transforma de imediato na mais completa representação e ilusão. Ainda assim, nenhuma concepção viável de realismo é possível a menos que ambas essas exigências e pretensões sejam atendidas, ao mesmo tempo, prolongando e preservando - mais do que "resolvendo" - essa tensão e incomensurabilidade constitutivas (JAMESON, 1995, p.162).

O que acaba sendo muito instigante, seguindo tal linha de raciocínio, é exatamente essa instabilidade conceitual que, no entendimento do filósofo, é o que lhe confere interesse e valor históricos.

Pois bem, para além da intenção explícita de trazer à luz uma das problemáticas mais candentes da atualidade, a obra de Gaglianone é singular, justamente por ter a ousadia de enfrentar o tema do paradoxo do realismo na contemporaneidade.

De saída, seu projeto fílmico é ficcional: tem-se a sala de aula, professor e alunos imigrados num claro processo de representação. Mas, concomitante a isso, há também uma proposta que se abre ao documentário, uma vez que os alunos se autorrepresentam, narram suas histórias de vida e na sala de aula encontram um espaço de livre expressão.

Ainda que estejamos sempre no campo da representação, a ideia de quebrar a quarta parede, de aproximar o espectador dos bastidores do "fazer cinema", numa investida metacinematográfica, é já uma forte ruptura com o ilusionismo, o que está a indicar, com todas as letras, um chamamento a que participemos como cúmplices e também quebremos o muro que nos separa daquele outro, estrangeiro, tão distante e ao mesmo tempo, tão próximo.

O cinema que reflete sobre o próprio fazer cinematográfico, aqui, tem o propósito explícito de atrair o espectador para dentro do set de filmagem. Assim, de certa forma, quebra não apenas 
a quarta parede, mas também a enorme distância que nos separa daqueles imigrados.

Quando a realidade invade a cena, trazendo à tona o problema a ser enfrentado por um dos alunos e a impotência de toda a equipe de filmagem diante daquele fato, rompe-se o halo protetor da representação. Em outras palavras, ao desestabilizar a câmera, abrindo-se a filmar o "choque do real", o cinema de Gaglianone escancara o paradoxo conceitual do realismo, apontado por Jameson, na medida em que sua premissa estética é posta em xeque e o que se tem é, acima de tudo, a própria representação em crise. No limite, o que paira na cena, a partir de então, é a seguinte pergunta: como representar esse absurdo do real? E o questionamento é tão desconcertante que o próprio diretor, em entrevista já referida acima, chega a pensar em desistir de realizar o filme.

Importante perceber que, ao decidir trabalhar com a zona limítrofe entre o que é representação e o que é real, explicitando a impossibilidade de demarcar um gênero cinematográfico classificatório, o diretor assume sua postura de clara intervenção ideológica pró imigrado.

A multiplicidade étnica que, no filme, apresenta-se complexa, envolvendo alunos das mais variadas procedências e faixas etárias, afasta todo tipo de visão nacionalista ou essencialista, alinhando-se claramente a uma das vertentes dos Estudos do Multiculturalismo, denominada "Multiculturalismo Policêntrico".

A propósito, Robert Stam (2015), retomando o que propõe Joan Scott em Multiculturalism and the politics of identity (1992) e Stuart Hall em "Minimalselves" na obra Identity: the real me (1987), observa a existência desse tipo de tendência, transpondo-a para a teoria do cinema, lembrando que esta exige mudanças não apenas no tocante às imagens, mas às relações de poder, apregoando uma solidariedade que se manifesta nitidamente em relação aos sub-representados e aos marginalizados.

Para o famoso estudioso de cinema, enquanto o pluralismo liberal segue um esquema apaticamente aditivo, que benevolentemente "inclui" outras vozes no interior de um mainstream preexistente, o multiculturalismo policêntrico é celebratório, identificando as chamadas comunidades minoritárias como participantes ativos e produtores, localizados no próprio centro de uma história compartilhada e conflituosa (STAM, 2015, p.298).

Além disso, nesse tipo de proposta, há a clara rejeição de um conceito de identidades ou comunidades unificado, fixo e essencialista. O que predomina é a percepção das identidades como múltiplas, instáveis e historicamente situadas, resultados de uma diferenciação progressiva e de identificações polimórficas:

O multiculturalismo policêntrico vai além das definições estritas da política de identidade, constituindo espaços para uma afiliação esclarecida com base em desejos e identificações sociais compartilhadas... O multiculturalismo policêntrico é recíproco e dialógico; de sua perspectiva, a totalidade dos atos de troca verbal ou cultural ocorre não entre indivíduos ou culturas essenciais, discretos e delimitados, mas entre indivíduos e culturas permeáveis e em 
permanente modificação (STAM, 2015, p.298, 299).

A sala de aula, no filme de Gaglianone, passa ser o lugar possível, o espaço em que eles podem existir, deixando de ser invisíveis, um microterritório provisoriamente seguro em que surgem como indivíduos com identidades próprias, que valem mais do que qualquer certificado de permanência ${ }^{4}$. É o local em que se celebram as diferenças dialogicamente, em que juntos (apesar de todas as suas idiossincrasias originárias), em voz coral, narram a tragédia de suas respectivas diásporas e mostram-se permeáveis às trocas que naquele contexto aparecem.

Obviamente, as questões levantadas giram ao redor das necessidades básicas da integração do imigrado: moradia, trabalho, família, assumindo um tom altamente irônico, por exemplo, quando o professor lhes oferece uma caixa em que devem depositar papéis em que serão escritos, de um lado, os "direitos" e outra, em que devem ser inseridos os "deveres".

Todos esses argumentos são postos em cena numa pluralidade de pensamentos e experiências que se trocam, ora jocosas como quando um dos alunos corrige o modo de falar do colega ao lado, ora dramáticas, como no momento em que são evocadas as lembranças do que ficou para trás, depois da terrível travessia.

Diante do trauma, há os que contam para viver, numa experiência catártica de exposição, mas há também os que emudecem e a força de seu silêncio é, por vezes, tão cortante, que acaba por revelar mais intensamente a dor da partida do que se esta fosse narrada com todas as letras.

De toda forma, essa multiplicidade étnica não é apenas apresentada, mas celebrada na proposta fílmica de Gaglianone, o que também indica mais um fator distintivo de um cinema que marca posição na análise das representações das minorias. Para Robert Stam, várias subcorrentes cinematográficas mesclam-se na corrente mais ampla do que se poderiam denominar "estudos midiáticos multiculturais": a análise de representação da "minoria"; a crítica da mídia imperialista e orientalista; o trabalho sobre o discurso colonial e pós-colonial; a teorização do "Terceiro Mundo" e do "Terceiro Cinema"; o trabalho sobre a "mídia nativa"; o trabalho sobre os cinemas "minoritários", "diaspóricos" e de "exílio"; os estudos sobre a "branquidade"; e o trabalho com a pedagogia da mídia antirracista e multicultural (STAM, 2015, p.299).

Concordando com o que o próprio diretor afirma em uma de suas entrevistas, seu filme evita o percurso fácil de colocar em evidência pessoas em situações difíceis, para as quais é imperativo dirigir um olhar comovido e solidário. Em outras palavras, muitas vezes, os apelos retóricos podem assumir uma dimensão que resvala a hipocrisia subjacente a todas as relações de poder, o que é contraproducente.

La mia classe tem evidentemente um traço antirretórico, que se explicita quando decide enfrentar o estatuto paradoxal da antirrepresentação cinematográfica. Com efeito, no entendimento do produtor e roteirista de cinema e televisão, Pedro Eduardo Pereira Salomão:

$4 \quad$ Num trecho do filme, os alunos estão conversando em sala de aula sobre os papéis necessários para sua integração na Itália. Vem à baila a seguinte reflexão, a partir de uma observação de Issa: "o Certificado de Permanência então vale mais do que a nossa própria identidade?" 
Adesestabilização dos conceitos de ficção e não-ficção impõe uma reordenação no espaço reservado à realidade dentro do universo fílmico contemporâneo. Os fragmentos da realidade intercalados a passagens ficcionalizadas não se limitam a uma co-presença, a serem um pano de fundo para a ficção. São mais que isso, interferindo fortemente na construção dramatúrgica e no conceito de verossimilhança do espectador. (SALOMÃO, 2007, s/p)

À desestabilização da representação, na proposta de Gaglianone, corresponde a impotência de ação diante da realidade abjeta. É esse o nó crucial que La mia classe não consegue desatar e que é poeticamente revelado na brilhante atuação final de Mastandrea. Sentado em sua cadeira de professor, na mesma sala de aula, dirige-se presumivelmente aos alunos e à câmera, declamando o seguinte monólogo:

Sono in una città straniera e sto camminando lungo un fiume, piove, piove sempre. In giro non c'è nessuno. Ad un certo punto vedo qualcosa che mi viene incontro, lentamente lo riconosco è un cane, un cane magro, bagnato; quando mi vede rallenta, rallento anch'io. Gli faccio una carezza, due, forse tre. Poi mi alzo e continuo a camminare. Lui viene con me, mi accompagna a casa. Lo guardo e non mi sta guardando, cammina con me, come se fosse il mio cane. Arriviamo davanti al portone, che non è un portone, non c'è una porta, è un arco, poi dentro c'è una scala e a metà di questa scala c'è un cancello con delle sbarre. Mi fermo, lo guardo e lui mi guarda come a dire: "Beh, andiamo". Non può venire con me, non lo posso portare. La padrona di casa è stata chiara: niente animali in casa! Allora cammino, apro il cancello, lo richiudo. Lui fa qualche scalino e si accuccia sull'ultimo accanto al cancello. Allora mi siedo anch'io e rimaniamo così, uno da una parte e uno dall'altra. Passano 5-10 minuti, non lo so, mi alzo e faccio per andare a casa e lui mi vede andare via e inizia a gridare, a urlare, non sta abbaiando, sta strillando. Poi inizia a scagliarsi con violenza contro il cancello e mi fa paura, io ho paura che se non ci fosse quel cancello lui mi salterebbe addosso e mi azzannerebbe. Scappo verso casa e spero che il cane vada via e invece quando mi chiudo la porta alle spalle lo sento ancora gridare, gridare che sono un traditore. (MASTANDREA, in GAGLIANONE, 2013, epilogo)

Quando sua fala termina, a câmera sai do close do professor e focaliza a sala de aula, que ao contrário do que se supunha, já não tem mais nenhum aluno, está completamente vazia. $\mathrm{O}$ monólogo não se dirigia a ninguém, o que faz concluir que, aos poucos, todos os alunos deixaram de participar do filme, provavelmente por estarem impedidos por lei. Tal esvaziamento 
nos faz refletir sobre um dos desabafos do ator Mastandrea ao diretor, quando se vê diante da impossibilidade de agir concretamente em relação ao problema de Issa: “- Então, aquilo que estamos fazendo não serve para nada...” (MARSHALL, 2014, p. 71)

Daniele Gaglianone marca, sem dúvida, uma posição singular na história do cinema italiano contemporâneo que tem se debruçado sobre a problemática migratória. Sem descurar de um conteúdo abertamente alinhado à causa pró-imigrado, inova formalmente, na medida em que se utiliza de procedimentos que, em última instância, quebram o ilusionismo, encenando o drama da própria representação em crise, numa interessante proposta metacinematográfica, em que documentário e ficção se embaralham propositalmente. 


\section{Referências}

AGIS SCUOLA. Schede film: La mia classe, c2014. Disponível em: https://agiscuola.it/schede-film/ item/353-la-mia-classe.html. Acesso em: 05/03/2017.

GAGLIANONE, D. La mia classe [dvd]. Italia: Axelotil Film \& Kimera film Relief com RaiCinema, 2013, em cores; 95 min.; Direção: Daniele Gaglianone; Roteiro: Gino Clemente, Daniele Gaglianone, Claudia Russo. Elenco: Valerio Mastandrea, Bassirou Ballde, Mamon Bhuiyan, Gregorio Cabral, Jessica Canahuire Laura.

JAMESON, F. As marcas do visível. Trad: Ana Lúcia de Almeida Gazolla, João Roberto Martins Filho, Klauss Brandini Gerhardt, Marcos Soares, Neide Aparecida Silva, Regina Thompson, Roneide Venancio Majer. Rio de Janeiro: Graal, 1995, p.162.

MARSHALL, L. Una lezione per tutti. Internazionale. Sezione Cultura, Roma, $\mathrm{n}^{\circ}$ 1034, 17-23 gennaio 2014, p. 70-71. Disponível em: http://http://blog.mondodigitale.org/wp-content/uploads/2014/01/ Laclasse-internazionale.pdf. Acesso: 05/03/2017.

NICHOLS, B. Introdução ao documentário. Trad. Mônica Saddy Martins. Campinas: Papirus, 2014.

SALOMÃO, P. E. P. O paradoxo do realismo no cinema contemporâneo. In: Digitarama, Revista Acadêmica de Cinema. Rio de Janeiro, $\mathrm{n}^{\circ}$ 4, jan-jul 2007, s/p. Disponível em: em: http://www.estacio.br/ graduacao/ cinema/ digitagrama/ numero4/pedroeduardo.asp. Acesso: 06/07/2016.

STAM, R. Introdução à teoria do cinema. Trad. Fernando Mascarello. Campinas: Papirus, 2015.

Recebido: 15/06/2018

Aprovado: 13/09/2018 